ORIGINAL ARTICLE

\title{
Associations between perinatal interventions and hospital stillbirth rates and neonatal mortality
}

\author{
R Joyce, R Webb, J L Peacock
}

Arch Dis Child Fetal Neonatal Ed 2004;89:F51-F56

See end of article for authors' affiliations

Correspondence to: Dr Joyce, Bedfordshire Heartlands Primary Care Trust, 1-2 Doolittle Mill

Froghall Road, Ampthill, Bedfordshire MK45 2NX, UK; rioyce@doctors.org.uk

Accepted 17 January 2003
Background: Previous studies suggest that high risk and low birthweight babies have better outcomes if born in hospitals with level III neonatal intensive care units. Relations between obstetric care, particularly intrapartum interventions and perinatal outcomes, are less well understood, however.

Objective: To investigate effects of obstetric, paediatric, and demographic factors on rates of hospital stillbirths and neonatal mortality.

Methods: Cross sectional data on all 65 maternity units in all Thames Regions, 1994-1996, covering 540834 live births and stillbirths. Hospital level analyses investigated associations between staffing rates (consultant/junior paediatricians, consultant/junior obstetricians, midwives), facilities (consultant obstetrician/anaesthetist sessions, delivery beds, special care baby unit, neonatal intensive care unit cots, etc), interventions (vaginal births, caesarean sections, forceps, epidurals, inductions, general anaesthetic), parental data (parity, maternal age, social class, deprivation, multiple births), and birthweight standardised stillbirth rates and neonatal mortality.

Results: Unifactorial analyses showed consistent negative associations between measures of obstetric intervention and stillbirth rates. Some measures of staffing, facilities, and parental data also showed significant associations. Scores for interventional, organisational, and parental variables were derived for multifactorial analysis to overcome the statistical problems caused by high intercorrelations between variables. A higher intervention score and higher number of consultant obstetricians per 1000 births were both independently and significantly associated with lower stillbirth rates. Organisational and parental factors were not significant after adjustment. Only Townsend deprivation score was significantly associated with neonatal mortality (positive correlation).

Conclusions: Birthweight adjusted stillbirth rates were significantly lower in units that took a more interventionalist approach and in those with higher levels of consultant obstetric staffing. There were no apparent associations between neonatal death rates and the hospital factors measured here.
$\mathrm{S}$ everal factors are potentially responsible for variations in hospital stillbirth rates and neonatal mortality in developed countries, including case mix of births and quality of care.

The link between clinical risk of the baby and its outcomes ${ }^{12}$ is well known. However, there is limited research on the possible relation between hospital obstetric (particularly intrapartum) practice and extended perinatal outcomes. $^{3-9}$ More is known about the links between paediatric neonatal care and mortality. These studies suggest that infants from high risk and low birthweight births are less likely to die if born in more specialised units and that in utero transfers are safer than ex utero. ${ }^{10-17}$ Although the link between perinatal outcomes and factors such as deprivation and maternal age is also well known, ${ }^{12}$ there is little research showing how such factors may affect the relation between obstetric and paediatric care and stillbirth rates and neonatal mortality. This study investigates the effects and interrelationships of obstetric factors (staffing, organisation of departments, and intrapartum interventions), paediatric factors (neonatal intensive care units (NICUs), special care baby units (SCBUs), and staffing) and parental data on hospital stillbirth rates and neonatal mortality.

\section{METHODS}

Definitions

- Stillbirth rate: number of babies born dead after 24 weeks gestation per 1000 live births and stillbirths.
- Neonatal mortality: number of liveborn babies who die within the first 28 days of life per 1000 liveborn babies.

\section{Data and statistical methods}

Four national and one regional data source were chosen. This was necessary to ensure accurate and complete data. The same data collection techniques were used for each of these sources at each hospital studied, to ensure comparability between units. The national data sources were Office for National Statistics (ONS) birth and death registrations, the 1991 Census, Royal College of Obstetricians and Gynaecologists (RCOG) hospital recognition returns, and Department of Health (DOH) data on hospital staffing levels. The regional data source was a survey of risk management practices in all Thames maternity units, performed in 1997 by the North Thames midwifery supervisor. All births in all Thames Regions hospitals (UK) in 1994-1996 were included in the study. ONS data were obtained for each of these live births and stillbirths and their linked neonatal death registrations.

These individual data from ONS were then linked to 1991 small area level Census data in an anonymous way. Townsend deprivation scores ${ }^{18}$ were obtained for each birth

Abbreviations: DOH, Department of Health; ONS, Office for National Statistics; NICU, neonatal intensive care unit; RCOG, Royal College of Obstetricians and Gynaecologists, SCBU, special care baby unit 
Table 1 Data used for analysis for each hospital, Thames hospitals, 1994-1996

\begin{tabular}{|c|c|c|c|c|c|}
\hline Variable & $\begin{array}{l}\text { Data source (numerator/ } \\
\text { denominator where different) }\end{array}$ & Mean & SD & Range & $\mathbf{N}$ \\
\hline Mean number of births per year & ONS birth and death registrations & 2877 & 807.7 & $872-4214$ & 64 \\
\hline Mean birth weight* & ONS birth and death registrations & 3306 & 75.0 & $3011-3423$ & 64 \\
\hline Crude stillbirth rate & ONS birth and death registrations & 5.69 & 2.008 & $1.93-12.42$ & 64 \\
\hline Crude neonatal mortality & ONS birth and death registrations & 3.54 & 2.289 & $1.11-11.73$ & 64 \\
\hline Standardised stillbirth rate & ONS birth and death registrations & 5.84 & 1.253 & $3.40-8.53$ & 64 \\
\hline Standardised neonatal mortality & ONS birth and death registrations & 3.48 & 0.827 & $1.90-5.39$ & 64 \\
\hline $\begin{array}{l}\text { Mean number of consultant } \mathrm{O} \& \mathrm{G} \\
\text { sessions on labour ward per week }\end{array}$ & RCOG hospital recognition returns & 2.5 & 2.45 & $0-10$ & 40 \\
\hline $\begin{array}{l}\text { Mean number of consultant anaesthetic } \\
\text { sessions on labour ward per week }\end{array}$ & RCOG hospital recognition returns & 4.1 & 1.78 & $1-10$ & 60 \\
\hline Delivery beds per 1000 deliveries & RCOG hospital recognition returns/ONS registrations & 3.6 & 0.80 & $2.4-6.6$ & 60 \\
\hline NICU cots per 1000 deliveries & RCOG hospital recognition returns/ONS registrations & 1.3 & 1.13 & $0-6.8$ & 60 \\
\hline SCBU and NICU cots per 1000 deliveries & RCOG hospital recognition returns/ONS registrations & 6.1 & 2.10 & $2.6-17.0$ & 60 \\
\hline Spontaneous vaginal deliveries per 100 births & RCOG hospital recognition returns & 71.0 & 5.35 & $53.0-81.5$ & 60 \\
\hline Vaginal breech births per 100 breeches & RCOG hospital recognition returns & 23.7 & 11.80 & $1.5-52.5$ & 60 \\
\hline Emergency caesareans per 100 breeches & RCOG hospital recognition returns & 27.7 & 11.63 & $0-51.5$ & 45 \\
\hline Elective caesareans per 100 breeches & RCOG hospital recognition returns & 48.4 & 12.36 & $18.3-73.9$ & 45 \\
\hline Number of caesarean sections per 100 deliveries & RCOG hospital recognition returns & 18.0 & 3.84 & $8.0-33.4$ & 60 \\
\hline Number of forceps per 100 births & RCOG hospital recognition returns & 5.0 & 1.88 & $2.3-10.1$ & 60 \\
\hline Number of vacuum deliveries per 100 births & RCOG hospital recognition returns & 6.0 & 2.31 & $1.8-12.3$ & 60 \\
\hline $\begin{array}{l}\text { Total number of instrumental vaginal deliveries per } 100 \\
\text { births }\end{array}$ & RCOG hospital recognition returns & 11.1 & 2.68 & $5.0-19.1$ & 60 \\
\hline Number of inductions per 100 deliveries & RCOG hospital recognition returns & 19.6 & 4.45 & $11.9-40.0$ & 59 \\
\hline Number of epidurals per 100 deliveries & RCOG hospital recognition returns & 31.8 & 13.66 & $9.7-74.7$ & 59 \\
\hline Number of epidurals for labour per 100 deliveries & RCOG hospital recognition returns & 20.3 & 10.53 & $2.6-55.5$ & 59 \\
\hline $\begin{array}{l}\text { Number of general anaesthetics per } 100 \text { caesarean } \\
\text { sections }\end{array}$ & RCOG hospital recognition returns & 30.8 & 11.80 & $1.5-52.5$ & 60 \\
\hline Number of consultant paediatricians per 1000 births & DOH staffing data/ONS registrations & 1.2 & 0.53 & $0.34-3.26$ & 57 \\
\hline Number of junior paediatricians per 1000 births & $\mathrm{DOH}$ staffing data/ONS registrations & 2.9 & 1.03 & $0.9-6.5$ & 56 \\
\hline Number of consultant O\&Gs per 1000 deliveries & DOH staffing data/ONS registrations & 1.4 & 0.63 & $0.7-4.7$ & 58 \\
\hline Number of junior O\&Gs per 1000 deliveries & DOH staffing data/ONS registrations & 4.3 & 2.34 & $0.5-18.3$ & 58 \\
\hline Number of midwives per 1000 deliveries & DOH staffing data/ONS registrations & 29.6 & 6.62 & $18.3-47.0$ & 49 \\
\hline Percentage of births to nulliparous women & ONS birth and death registrations & 41.0 & 4.17 & $32.4-58.6$ & 64 \\
\hline Percentage of births to teenage mothers & ONS birth and death registrations & 5.0 & 1.77 & $2.0-10.0$ & 64 \\
\hline Percentage of births to women $>40$ years old & ONS birth and death registrations & 2.2 & 0.75 & $1.0-4.7$ & 64 \\
\hline Percentage of births to fathers of manual or "other" class & ONS birth and death registrations & 50.4 & 10.69 & $27.0-72.3$ & 64 \\
\hline $\begin{array}{l}\text { Mean Townsend deprivation score of babies born } \\
\text { in hospital }\end{array}$ & $\begin{array}{l}1991 \text { Census and ONS registrations (Census data for } \\
\text { enumeration district of residence of each birth) }\end{array}$ & 1.0 & 2.34 & $-2.2-7.1$ & 64 \\
\hline Percentage of babies from multiple births & ONS birth and death registrations & 2.9 & 1.08 & $0.5-10.1$ & 64 \\
\hline $\begin{array}{l}\text { Does unit have a } 24 \text { hour epidural service (see } \\
\text { table 3)? }\end{array}$ & RCOG hospital recognition returns & - & - & - & 40 \\
\hline $\begin{array}{l}\text { Does unit have a dedicated maternity theatre (see } \\
\text { table 3)? }\end{array}$ & RCOG hospital recognition returns & - & - & - & 40 \\
\hline Does unit have a risk manager (see table 3 )? & Thames risk management survey & - & - & - & 50 \\
\hline Grade of risk manager (see table 3 ) & Thames risk management survey & - & - & - & 49 \\
\hline Frequency of perinatal meetings (see table 3) & Thames risk management survey & - & - & - & 50 \\
\hline
\end{tabular}

from their enumeration district of residence, enabling the calculation of a mean deprivation score for each hospital population. Table 1 shows data available for each hospital and their source.

Crude and birthweight standardised (500 g band) stillbirth rates and neonatal mortality were calculated for each hospital. Direct standardisation was not possible because of inadequate numbers of deaths in birthweight bands and so we used $500 \mathrm{~g}$ band indirect standardisation for birth weight as a proxy for case mix adjustment. This has been shown to be a reliable surrogate in the absence of more detailed clinical information on these births. ${ }^{19}{ }^{20}$ Birthweight specific mortality was also calculated. Intervention and facility and staffing rates were calculated from numerators and denominators (table 1). RCOG numerators were used with RCOG denominators to maintain internal consistency.

Factors related to crude and standardised mortality were initially analysed using simple regression, $t$ tests, and analysis of variance as appropriate. The variables under investigation were grouped into four types: those relating to facilities, interventions, staffing, and parental data. To disentangle the effects of these various factors, we used multiple regression analysis.

During analysis of the variables within the four groups described above, it became apparent that some variables within groups were highly intercorrelated making it difficult to disentangle them from each other. This was particularly true for the variables in the "intervention" group, where many were significantly related to the outcome and were highly intercorrelated. In other words it was impossible to identify individual factors that were more strongly associated with the outcome than others as they all appeared to be measuring a common effect. In such situations the statistical method, Principal Components Analysis, can be used. This method works by combining the variables within a group into scores that represent the common effect of those variables more concisely than the original variables were able to. The method of Principal Components typically produces one or two scores that summarise the overall effects of all the variables in the group.

This statistical technique was used for each conceptual group, and thus led to one or two scores for the facilities, 
intervention, and parental data groups (only one variable was significant for staffing). These variables were used in multiple regression analyses in the four groups separately in the first instance. Variables that were significant in the four groups separately were then entered into a further multiple regression model where the least significant variables were eliminated in turn, in a stepwise fashion (backwards stepwise regression). This was repeated until all remaining variables were significant.

To confirm the robustness of these results, we also performed different statistical analyses using a variety of techniques including forwards and backwards stepwise regression of all the variables and the same approach after regressions within conceptual groups. We also derived an arbitrary intervention score for each hospital. The results of these sensitivity analyses were all fully consistent with the results using multiple regression and the Principal Components Analysis described above (data not shown).

Distributional assumptions were tested using histograms and Normal plots and showed that no transformation of the data was required. SPSS and STATA were used for analysis.

\section{RESULTS}

ONS data were received for 540834 births (3150 stillbirths and 537684 live births, including 2088 neonatal deaths). This represented full cohorts for all 65 Thames hospitals. RCOG, staffing, and risk management data were also obtained for these hospitals. ONS, Census, and DOH staffing data were nearly $100 \%$ complete. RCOG returns for the years in question $(1994,1995 / 6,1996 / 7)$ were $83 \%, 66 \%$, and $86 \%$ complete respectively. However, only $5 \%$ failed to return for any year, making numerators and denominators available for 95\%. RCOG returns were $94 \%$ complete. This was the most comprehensive data source on hospital interventions available for this area. The risk management survey had an $84 \%$ response, with complete data on all forms when returned.

During the period under study, some hospitals closed or merged. For unit closures, data are presented for the years available. For mergers, the newly merged unit is recorded as a new hospital-for example, Guy's and Thomas' are recorded separately in 1994, and as a combined unit in 1995 and 1996. One hospital (Cambridge Military) was excluded, as it closed in 1994, only registered a small number of births, no deaths, and had no RCOG or risk management returns.

Figure 1 shows histograms of the crude and standardised stillbirth rates and neonatal mortality along with the very low birthweight $(<1500 \mathrm{~g})$ rates. The crude death rates were positively skewed, but standardisation appeared to correct this and gave distributions that were reasonably symmetrical. The residuals did in fact follow an approximately Normal distribution, and so we did not transform the data for analysis.

The crude hospital stillbirth rates correlated positively with the crude hospital neonatal death rates $(r=0.752$, $\mathrm{p}<0.001)$. Birth weight accounted for over $70 \%$ of the variability in crude death rates-that is, stillbirth rate and neonatal death rate combined (regression on mean birth weight, $R^{2}=0.708, \mathrm{p}<0.001$; regression on proportion of births $<1500 \mathrm{~g}, R^{2}=0.752, \mathrm{p}<0.001$; regression on proportion of births $\left.<2500 \mathrm{~g}, R^{2}=0.719, \mathrm{p}<0.001\right)$.

There were no significant effects of any hospital variable on standardised neonatal mortality. Of the parental variables, only Townsend deprivation score correlated positively (table 2). Many of the unifactorial analyses of standardised stillbirth rate were significant. In particular, there was strong consistency in the direction of the associations with intervention variables indicating a protective effect of intervention. Seven of the 12 results were significant. Of the staffing rates, only the number of obstetric consultants per 1000
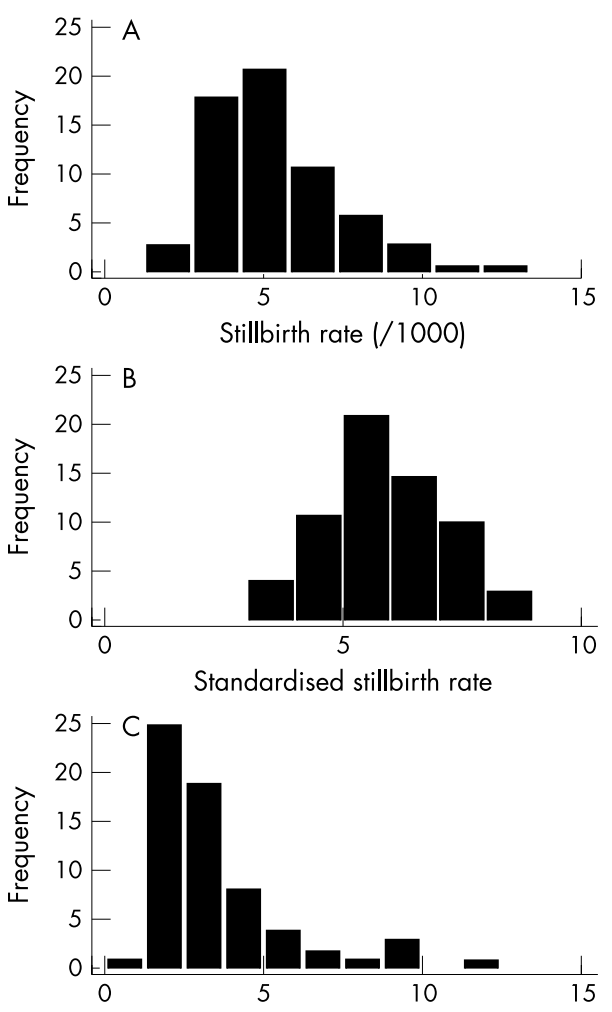

Neonatal mortality $(/ 1000)$
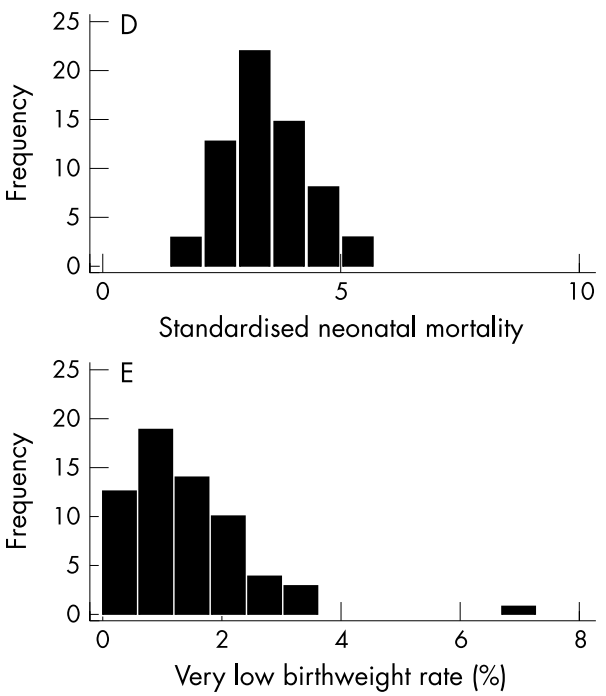

Figure 1 Histograms of the crude (A) and standardised (B) stillbirth rates and crude (C) and standardised (D) neonatal mortality and the very low birthweight $(<1500 \mathrm{~g}$ ) rates $(\mathrm{E})$, Thames hospitals, 1994-1996 $(\mathrm{n}=64)$.

births was significantly (negatively) related to stillbirth rates. Among the measures of facilities, there was a negative correlation between stillbirth rates and the number of NICU and SCBU cots. There was little evidence of any effect on either mortality or the measured risk management processes (table 3).

The seven significant "intervention" type variables were reduced to two principal components, of which only the first was significantly related to stillbirth rates (table 4 ). The two significant "facilities" variables were reduced to one principal component, and the three "parental" variables reduced to two components, one of which appeared to summarise a 
Table 2 Simple linear regressions where outcome variables are standardised stillbirth rates (SSBR) and standardised neonatal mortality (SNNM), Thames hospitals, 1994-1996

\begin{tabular}{|c|c|c|c|c|c|c|}
\hline \multirow[b]{2}{*}{ Predictor variable } & \multicolumn{3}{|l|}{ SSBR } & \multicolumn{3}{|l|}{ SNNM } \\
\hline & B (slope) & p Value & $R^{2}$ & B (slope) & p Value & $R^{2}$ \\
\hline \multicolumn{7}{|l|}{ Size of unit } \\
\hline Mean number of births per year & 0.000 & 0.21 & 0.026 & 0.000 & 0.64 & 0.004 \\
\hline \multicolumn{7}{|l|}{ Organisation and availability of facilities } \\
\hline $\begin{array}{l}\text { Mean number of consultant O\&G sessions on } \\
\text { labour ward/week }\end{array}$ & 0.066 & 0.45 & 0.010 & 0.095 & 0.10 & 0.046 \\
\hline $\begin{array}{l}\text { Mean number of consultant anaesthetic } \\
\text { sessions on labour ward/week }\end{array}$ & 0.069 & 0.44 & 0.010 & 0.041 & 0.51 & 0.008 \\
\hline Delivery beds per 1000 deliveries & 0.142 & 0.48 & 0.009 & 0.250 & 0.063 & 0.059 \\
\hline NICU cots per 1000 births & -0.378 & 0.006 & 0.123 & 0.145 & 0.13 & 0.039 \\
\hline SCBU and NICU cots per 1000 births & -0.153 & 0.04 & 0.070 & 0.071 & 0.17 & 0.033 \\
\hline \multicolumn{7}{|l|}{ Intervention rates } \\
\hline SVDs per 100 births & 0.088 & 0.002 & 0.148 & -0.014 & 0.49 & 0.008 \\
\hline Vaginal births per 100 breeches & 0.018 & 0.19 & 0.029 & 0.005 & 0.59 & 0.005 \\
\hline Emergency CS per 100 breeches & 0.003 & 0.820 & 0.001 & -0.007 & 0.35 & 0.020 \\
\hline Elective CS per 100 breeches & -0.017 & 0.16 & 0.044 & -0.005 & 0.49 & 0.011 \\
\hline CS per 100 deliveries & -0.091 & 0.026 & 0.083 & 0.047 & 0.09 & 0.048 \\
\hline Forceps per 100 births & -0.176 & 0.035 & 0.074 & -0.038 & 0.51 & 0.008 \\
\hline Vacuum deliveries per 100 births & 0.089 & 0.20 & 0.029 & 0.042 & 0.37 & 0.014 \\
\hline Instrumental deliveries per 100 births & -0.153 & 0.008 & 0.114 & 0.013 & 0.76 & 0.002 \\
\hline Inductions per 100 deliveries & -0.02 & 0.59 & 0.005 & 0.009 & 0.71 & 0.003 \\
\hline Epidurals per 100 deliveries & -0.036 & 0.001 & 0.167 & 0.002 & 0.82 & 0.001 \\
\hline Epidurals for labour per 100 deliveries & -0.042 & 0.005 & 0.130 & -0.001 & 0.93 & 0.000 \\
\hline GAs per $100 \mathrm{CSs}$ & 0.032 & 0.002 & 0.161 & -0.008 & 0.27 & 0.021 \\
\hline \multicolumn{7}{|l|}{ Staffing levels } \\
\hline Consultant paediatricians per 1000 births & -0.074 & 0.81 & 0.001 & -0.294 & 0.17 & 0.035 \\
\hline Junior paediatricians per 1000 births & -0.165 & 0.30 & 0.020 & -0.033 & 0.77 & 0.002 \\
\hline Consultant O\&Gs per 1000 deliveries & -0.681 & 0.006 & 0.130 & -0.045 & 0.80 & 0.001 \\
\hline Junior O\&G per 1000 deliveries & -0.097 & 0.16 & 0.036 & 0.011 & 0.82 & 0.001 \\
\hline Midwives per 1000 deliveries & 0.012 & 0.65 & 0.004 & -0.012 & 0.50 & 0.010 \\
\hline \multicolumn{7}{|l|}{ Parental factors } \\
\hline Percentage of nulliparous (married) women & -0.079 & 0.037 & 0.069 & -0.17 & 0.51 & 0.007 \\
\hline Percentage births to teenage mothers & 0.183 & 0.038 & 0.067 & 0.050 & 0.39 & 0.012 \\
\hline Percentage births to mothers $>40$ & -0.366 & 0.08 & 0.048 & 0.053 & 0.70 & 0.002 \\
\hline Percentage births to fathers of manual or "other" class & 0.039 & 0.008 & 0.108 & 0.009 & 0.34 & 0.015 \\
\hline Mean Townsend score & 0.083 & 0.22 & 0.024 & 0.106 & 0.016 & 0.090 \\
\hline Percentage of babies from multiple births & -0.485 & 0.001 & 0.173 & -0.062 & 0.53 & 0.006 \\
\hline
\end{tabular}

NICU, neonatal intensive care unit; SCBU, special care baby unit; O\&G, obstetric and gynaecology; SVD, spontaneous vaginal delivery; CS, caesarean section; GA, general anaesthetic.

social class effect and the other a multiple birth effect (table 4). Thus the intervention score, facilities score, two parental scores, and the number of consultant obstetricians per 1000 births were analysed together. After a series of backwards removals of the least significant variable, only the intervention score and the number of consultant obstetri- cians per 1000 births remained significant, (table 5). The effect of the interventionalist approach was stronger than that of the consultant obstetrician rate, as shown by the change in stillbirth rate, which is equivalent to an interquartile range change in intervention score and consultant rate (table 5). The direction of these effects was the same as

Table 3 Results of unpaired $t$ tests and analyses of variance to determine differences in standardised stillbirth rates (SSBR) and standardised neonatal mortality (SNNM), Thames hospitals 1994-1996

\begin{tabular}{|c|c|c|c|c|c|c|}
\hline \multirow[b]{2}{*}{ Variable } & \multirow[b]{2}{*}{ Group } & \multicolumn{2}{|l|}{ SSBR } & \multicolumn{2}{|l|}{ SNNM } & \multirow[b]{2}{*}{$\mathrm{N}$} \\
\hline & & Mean & p Value & Mean & p Value & \\
\hline 24 hour epidural service? & $\begin{array}{l}\text { Yes } \\
\text { No }\end{array}$ & $\begin{array}{l}5.81 \\
6.07\end{array}$ & 0.73 & $\begin{array}{l}3.55 \\
2.71\end{array}$ & 0.09 & $\begin{array}{l}37 \\
3\end{array}$ \\
\hline Dedicated maternity theatre? & $\begin{array}{l}\text { Yes } \\
\text { No }\end{array}$ & $\begin{array}{l}5.81 \\
6.41\end{array}$ & 0.51 & $\begin{array}{l}3.48 \\
3.57\end{array}$ & 0.88 & $\begin{array}{l}38 \\
2\end{array}$ \\
\hline Does unit have a risk manager? & $\begin{array}{l}\text { Yes, specifically for maternity } \\
\text { Yes, for the whole hospital } \\
\text { No }\end{array}$ & $\begin{array}{l}5.55 \\
5.71 \\
5.79\end{array}$ & 0.86 & $\begin{array}{l}3.64 \\
3.32 \\
3.32\end{array}$ & 0.41 & $\begin{array}{l}20 \\
23 \\
8\end{array}$ \\
\hline Grade of risk manager? & $\begin{array}{l}\text { Obstetrician } \\
\text { Midwife manager } \\
\text { Clinical midwife } \\
\text { Other } \\
\text { No risk manager }\end{array}$ & $\begin{array}{l}5.68 \\
5.83 \\
6.16 \\
5.40 \\
5.79\end{array}$ & 0.77 & $\begin{array}{l}3.95 \\
3.39 \\
3.92 \\
3.18 \\
3.32\end{array}$ & 0.13 & $\begin{array}{l}10 \\
12 \\
4 \\
16 \\
8\end{array}$ \\
\hline Frequency of perinatal meetings? & $\begin{array}{l}\text { Once a week } \\
\text { Once a fortnight } \\
\text { Once a month } \\
\text { Once every two months } \\
\text { Once a quarter } \\
\text { When a case happens }\end{array}$ & $\begin{array}{l}5.51 \\
5.6 \\
5.55 \\
6.22 \\
5.84 \\
6.31\end{array}$ & 0.85 & $\begin{array}{l}2.99 \\
3.46 \\
3.57 \\
3.28 \\
3.61 \\
3.05\end{array}$ & 0.61 & $\begin{array}{l}7 \\
1 \\
31 \\
4 \\
6 \\
2\end{array}$ \\
\hline
\end{tabular}


Table 4 Results of Principal Components Analysis

\begin{tabular}{|c|c|c|}
\hline Grouping & Coefficient for component 1 & Coefficient for component 2 \\
\hline \multicolumn{3}{|l|}{ Interventional: $\mathbf{7 8} \%$ total variation explained } \\
\hline Caesarean sections per 100 deliveries & 0.30084 & -0.64642 \\
\hline Epidurals per 100 deliveries & 0.45175 & 0.06840 \\
\hline Epidurals in labour per 100 deliveries & 0.42888 & 0.12588 \\
\hline Forceps deliveries per 100 births & 0.25542 & 0.54584 \\
\hline General anaesthetics per 100 caesareans & -0.38094 & 0.03448 \\
\hline Spontaneous vaginal deliveries per 100 births & -0.39276 & 0.38424 \\
\hline Instrumental vaginal deliveries per 100 births & 0.39606 & 0.33888 \\
\hline Variability explained by component & $64 \%$ & $14 \%$ \\
\hline \multicolumn{3}{|l|}{ Facilities: $90 \%$ total variation explained } \\
\hline NICU cots per 1000 deliveries & 0.70711 & NA \\
\hline SCBU cots per 1000 deliveries & 0.70711 & \\
\hline Variability explained by component & $90 \%$ & \\
\hline \multicolumn{3}{|l|}{ Parental: $88 \%$ total variation explained } \\
\hline Percentage births to teenage mothers & 0.56459 & 0.22933 \\
\hline Percentage births with fathers of manual social class & 0.59464 & 0.16133 \\
\hline Percentage of babies from multiple births & -0.20234 & 0.95808 \\
\hline Percentage of births to nulliparous women & -0.53544 & 0.05892 \\
\hline Variability explained by component & $64 \%$ & $24 \%$ \\
\hline
\end{tabular}

Note: Consultant O\&G per 1000 deliveries was the only 'staffing' variable to be included and so was not included in the Principal Components Analysis. NICU, Neonatal intensive care unit; SCBU, special care baby unit; O\&G, obstetric and gynaecology.

for the univariate analyses as before, suggesting a protective effect of obstetric interventions and of higher rates of consultant obstetricians.

\section{DISCUSSION}

This is to our knowledge the first study that sets out to determine the relation between intrapartum intervention rates and stillbirth and neonatal death rates after the adjustment for case mix. To investigate factors that are hospital related, such as facilities and staff available and the clinical approach of a unit, it was necessary to conduct the analyses at the hospital level. Data on individual births were therefore aggregated to provide detailed information at the hospital level. No other study design could have answered these questions, and we were fortunate to obtain access to data on a large population with such heterogeneity of obstetric and neonatal services.

We found that the units with more interventionist approaches - that is, higher rates of obstetric intrapartum interventions-and those with higher levels of consultant obstetric staffing had lower stillbirth rates. The effect was much stronger for intrapartum interventions.

The findings of the analyses for standardised neonatal mortality were largely unremarkable on their own. The only significant factor was Townsend deprivation score, which would have been expected from the literature.

In contrast, the results for standardised stillbirth rate showed a clear pattern. Many of the significant results showed associations between various obstetric interventions and improved outcomes. The consistency of the relations, alongside the numbers of significant results and the large amounts of variability accounted for, suggests that these were not chance findings.

The statistical analysis of factors associated with stillbirth rates used Principal Components Analysis to overcome the inherent difficulty of disentangling the effects of several intercorrelated factors and to avoid an overfitted model. The findings of the multifactorial analyses were consistent with the unifactorial analyses, and therefore yielded no surprises. Further, the analyses of the data using other methods also showed the same results, indicating that these findings were not simply a product of a particular method of statistical analysis.

Despite the difficulty of disentangling the individual effects of the interventions, many of the associations appeared to be measuring the same effect. The effect observed appeared to be that of an association of the "interventionist approach" with improved outcomes. The association of worse outcomes with spontaneous vaginal delivery rates reflected the same effect, as did the non-significant positive correlations with vaginal birth and emergency-that is, unplanned-caesarean section rates for breech deliveries.

The only significant hospital related variable that was relevant postnatally was the number of NICU cots per 1000 births. It was non-significant for standardised neonatal mortality but it was significantly negatively correlated with standardised stillbirth rates-that is, protective. Obviously, this effect cannot be causal, as NICUs do not treat babies before birth. Moreover, clinical practice may tend to favour babies with poorer prognoses being referred to units with higher rates of NICU cots, therefore making our findings even more unexpected. This finding could reflect intercorrelations between interventionalist units and high rates of NICU cots. The effect was no longer significant after adjustment, indicating that this was not an independent effect of the neonatal unit.

The strong negative correlation with stillbirth rates and consultant obstetric staffing levels was not seen with other staffing levels (including midwives, paediatricians, and junior obstetricians). The finding may reflect the more

Table 5 Final multiple regression model for standardised stillbirth rate (SSBR)

\begin{tabular}{llllll}
\hline Model & B & SE & P Value & $\boldsymbol{R}^{2}$ & $\begin{array}{l}\text { Equivalent change in SSBR for IQR change in } \\
\text { predictor variable }\end{array}$ \\
\hline $\begin{array}{l}\text { Intervention score* (higher score } \geqslant \text { more } \\
\text { interventions) }\end{array}$ & -0.21 & 0.07 & 0.003 & 0.27 & -0.52 \\
No of consultant obstetricians per 1000 births & -0.55 & 0.23 & 0.019 & & -0.26 \\
\hline
\end{tabular}

*Intervention score, First Principal Component and is therefore standardised to have mean 0.0 overall.

$I Q R$, Interquartile range. IQR for intervention score $=2.47$. IQR for number of consultant obstetricians per 1000 births $=0.48$. 
experienced judgment that consultant obstetricians can offer on when it is best to intervene or not to intervene in an individual woman's pregnancy or labour. Therefore it is not surprising that this variable had an effect that was independent of intervention rates. This supports the commitment of RCOG to the principle of a consultant based workforce, with a greater commitment to emergency and on call duties. ${ }^{21}$ However, the effect was less than that of obstetric interventions. There were no data available on neonatal nurse staffing levels, so we were unable to rule out an association with mortality and levels of this group of staff. Our findings are consistent with the UK Neonatal Staffing Study, ${ }^{22}$ which found that risk adjusted neonatal mortality was related to nursing workload, but not to number of very low birthweight infants, paediatric consultant availability, or nursing provision.

The positive association of standardised stillbirth rates with factors representing "social class" could be expected from the literature..$^{23}$ The effects of social class on perinatal outcomes can be mediated either through fetal health or access to optimal care. Standardisation for birth weight would have removed much of the effects of fetal health. The fact that social class was not significant after adjustment may simply reflect the association between socioeconomic status and intervention rates mediated through patient demands and expectations. ${ }^{824} 25$

In summary, the findings of this study indicate that both an interventionist obstetric approach and higher levels of consultant obstetric staff are associated with reductions in standardised stillbirth rates. Birth weight accounts for most of the variability in stillbirth rates and neonatal mortality. When this has been adjusted for, perinatal units with a more "interventionist approach" and higher levels of consultant obstetric staff are associated with better outcomes in the form of lower stillbirth rates. These effects were shown before and after adjustment for other possible predictive and confounding factors. There is support for these findings in the temporal relations, consistency, and the strength of the relations.

It is unclear if there is a particular time period when this approach may be most associated with better outcomes-for example, antenatal or intrapartum-but overall low thresholds for intervening and more availability of consultant staff appears protective. Further work is needed to confirm our findings and determine possible reasons for them.

\footnotetext{
Authors' affiliations

R Joyce, J L Peacock, Department of Public Health Sciences, St George's Hospital Medical School, Cranmer Terrace, London SWI7 ORE, UK R Webb, South Thames West Perinatal Audit, Lower Ground Floor, Chiltern Court, 188 Baker Street, London NW1 5SD, UK
}

\section{REFERENCES}

1 Chamberlain G. Background to Perinatal Health. Lancet 1979:1061-3.

2 Macfarlane A, Mugford M, Johnson A, et al. Counting the changes in childbirth: trends and gaps in national statistics. Oxford: National Perinatal Epidemiology Unit, 1996.

3 Richardson DK, Gray JE, Gortmaker SL, et al. Declining severity adjusted mortality: evidence of improving Neonatal Intensive Care. Pediatrics 1998;102:893-9.

4 Bakketeigh LS, Hoffman HF, Sternthal PM. Obstetric service and perinatal mortality in Norway. Acta Obstet Gynecol Scand 1978;77(suppl): 1-19.

5 Confidential Enquiry into Stillbirths and Deaths in Infancy. CESDI 6th Annual Report. London: Maternal and Child Health Research Consortium, 1999.

6 Florey C, Taylor DJ. The relation between antenatal care and birth weight. Rev Epidemiol Med Soc Sante Publique 1994;42:191-7.

7 Joffe M, Chapple J, Paterson C, et al. What is the optimal caesarean section rate? An outcome based study of existing variation. J Epidemiol Community Health 1994:48:406-11.

8 Lomas J, Enkin M. Variations in operative delivery rates. Effective care in pregnancy and childbirth, Volume I. New York: Oxford University Press, 1989:1182-95.

9 Howell CJ. Epidural versus non-epidural analgesia for pain relief in labour. Cochrane Library, Issue 3. Oxford: Update Software, 1999.

10 Stilwell J, Szczepura A, Mugford M. Factors affecting the outcome of maternity care I: relationship between staffing and perinatal deaths at the hospital of birth. J Epidemiol Community Health 1988;42:157-69.

11 Powell SL, Holt VL, Hickok DE, et al. Recent changes in delivery site of low birth weight infants in Washington: impact on birth weight specific mortality. Am J Obstet Gynecol 1995;173:1585-92.

12 Cole SK, Macfarlane A. Safety and place of birth in Scotland. J Public Health Med 1995; 17:17-24

13 Finnstrom O, Olausson PO, Sedin G, et al. The Swedish national prospective study on extremely low birth weight (ELBW) infants. Incidence, mortality, morbidity and survival in relation to level of care. Acta Paediatr 1997;86:503-11.

14 Horbar JD, Badger GJ, Lewit EM, et al. Hospital and patient characteristics associated with variation in 28 -day mortality rates for very low birth weight infants. Pediatrics 1997;99:149-56.

15 Fresson J, Guillemin F, Ande M, et al. Influence of the transfer mode on shortterm outcome in newborns with high perinatal risk. Arch Pediatr 1997;4:219-26.

16 Yeast JD, Poskin M, Stockbauer JW, et al. Changing patterns in regionalization of perinatal care and the impact on neonatal mortality. Am J Obstet Gynecol 1998;178:131-5.

17 Field D, Draper ES. Survival and place of delivery following preterm birth: 1994-96. Arch Dis Child Fetal Neonatal Ed 1999;80:F111-15.

18 Townsend P, Phillimore P, Beattie A. Health and deprivation. London: Croon Helm, 1988.

19 Macfarlane A, Chalmers I, Adelstein AM. The role of standardisation in the interpretation of perinatal mortality rates. Health Trends 1990;12:45-50.

20 Hellier JL, Goldstein H. The use of birthweight and gestation to assess perinatal mortality risk. J Epidemiol Community Health 1979;33:183-5.

21 Royal College of Obstetricians and Gynaecologists. A blueprint for the future: a working party report on the future structure of the medical workforce and service delivery in obstetrics and gynaecology. London: RCOG Press, 2000.

22 The UK Neonatal Staffing Study Group. Patient volume, staffing, and workload in relation to risk-adjusted outcomes in a random stratified sample of UK neonatal intensive care units: a prospective evaluation. Lancet 2002;359:99-107.

23 Strobino DM, Ensminer ME, Kim YJ, et al. Mechanisms for maternal age differences in birth weight. Am J Epidemiol 1995;142:504-14.

24 Wilkinson C, Mcllwaine G, Boulton-Jones $C$, et al. Is a rising caesarian section rate inevitable? Br J Obstet Gynaecol, 1998; 105:45-52.

25 Shearer EL. Cesarian section: medical benefits and costs. Soc Sci Med 1993;37:1223-31. 